\title{
Designing ideal conduits for peripheral nerve repair
}

\author{
Godard C. W. de Ruiter, M.D., ${ }^{1}$ Martijn J. A. Malessy, M.D., Ph.D., 1 \\ Michael J. Yaszemski, M.D., Ph.D., 2 Anthony J. Windebank, M.D., ${ }^{3}$ \\ AND Robert J. SPInNER, M.D. ${ }^{2,4}$ \\ ${ }^{1}$ Department of Neurosurgery, Leiden University Medical Center, The Netherlands; and ${ }^{2}$ Departments of \\ Orthopedic Surgery and Laboratory for Biomedical Engineering, ${ }^{3}$ Neurology and Laboratory for \\ Neuroscience, and ${ }^{4}$ Neurosurgery, Mayo Clinic Rochester, Minnesota
}

\begin{abstract}
Nerve tubes, guides, or conduits are a promising alternative for autologous nerve graft repair. The first biodegradable empty single lumen or hollow nerve tubes are currently available for clinical use and are being used mostly in the repair of small-diameter nerves with nerve defects of $<3 \mathrm{~cm}$. These nerve tubes are made of different biomaterials using various fabrication techniques. As a result these tubes also differ in physical properties. In addition, several modifications to the common hollow nerve tube (for example, the addition of Schwann cells, growth factors, and internal frameworks) are being investigated that may increase the gap that can be bridged. This combination of chemical, physical, and biological factors has made the design of a nerve conduit into a complex process that demands close collaboration of bioengineers, neuroscientists, and peripheral nerve surgeons. In this article the authors discuss the different steps that are involved in the process of the design of an ideal nerve conduit for peripheral nerve repair. (DOI: 10.3171/FOC.2009.26.2.E5)
\end{abstract}

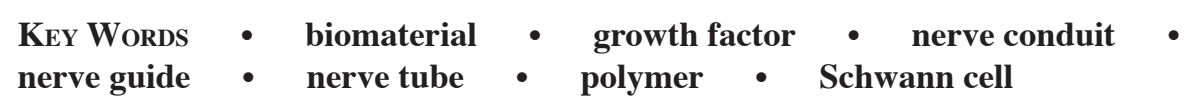

$I^{2}$ $\mathrm{N}$ the last 25 years, the concept of the nerve tube has evolved from a tool to investigate regeneration to a device that is now being used clinically in patients as an alternative for autologous nerve graft repair. Although their clinical use has been limited, mainly to the repair of relatively small defects $(<3 \mathrm{~cm})$ in small-caliber digital nerves, ${ }^{7,49,56}$ the potential for extending clinical application to the repair of larger defects and larger mixed or motor nerves ${ }^{48}$ has made the development of an ideal nerve tube appealing for both scientists and the medical device industry. At the moment several nerve tubes are being marketed (including Neurotube [Synovis], Neurolac [Ascension], SaluBridge [SaluMedica], and NeuraGen [Integra]). The basic design of these tubes (hollow tubes in which the nerve ends are inserted [Fig. 1]) is similar, but they are made of different biomaterials (synthetic: PGA, PLC, hydrogel; and natural: collagen) using various fabrication techniques (rolling of a mesh, ${ }^{13}$ precipitation on a rotating mandrel, ${ }^{33}$ or dip-coating of a rotating mandre ${ }^{14}$ ). As a result these nerve tubes also differ in physical properties. Currently, there is little information as to which tube functions better in the repair of small nerve gaps. In the original articles, ${ }^{4,5,13,15}$ all nerve

\footnotetext{
Abbreviations used in this paper: $\mathrm{BSA}=$ bovine serum albumin; FGF $=$ fibroblast growth factor; GDNF $=$ glial derived neurotrophic factor; NGF = nerve growth factor; $\mathrm{PGA}=$ polyglycolic acid; PLC $=\operatorname{poly}($ DL-lactide- $\varepsilon$-caprolactone $) ;$ PLGA $=$ poly $($ lactic-coglycolic acid).
}

tubes were reported to lead to results comparable to autograft repair. It is difficult, however, to compare the results of these studies, because different animal models, nerve gaps, and evaluation techniques were used. ${ }^{12}$ Also, functional results in most studies were not included, and physical properties were not determined for all conduits in detail. In our opinion therefore, there is still potential for improvement of even the common hollow nerve tube for the repair of small nerve gaps, especially because the goal of an ideal nerve tube is to perform better than the autograft.

In more recent years, research has been focused mainly on improving the single lumen nerve tube to bridge larger nerve gaps (Fig. 1 and Table 1). Different techniques have been applied to make nerve tubes permeable. Nerve tubes have been filled with collagen and laminin-containing gels, Schwann cells, and growth factors. Also, the internal microarchitecture of the nerve tube has been modified (for example, filaments, sponges, and multichannel nerve tube structures). Experimentally, these modifications have been demonstrated to increase the gap that can be bridged (Table 1). Clinically, however, the use is still limited, possibly because of practical disadvantages (for example, the harvest and culture of Schwann cells before reconstructive surgery) and because, in the repair of larger gaps, physical characteristics of the nerve tube become more important. This combination of chemical, physical, and biological factors has made the development of a nerve tube into a complex 


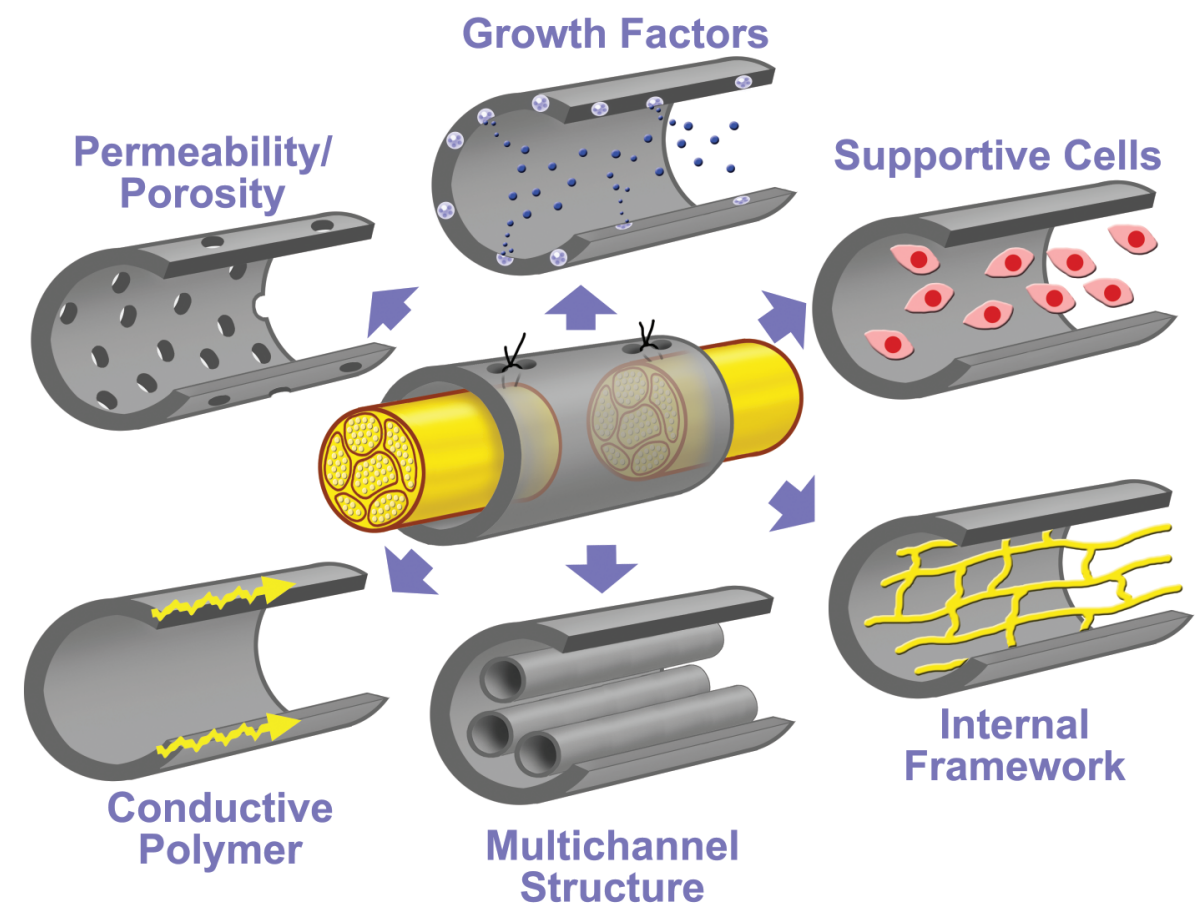

FIG. 1. Modifications to the single lumen nerve tube. Modified from Hudson TW, Evans, GR, Schmidt, CE: Engineering strategies for peripheral nerve repair. Clin Plast Surg 26:617-628, 1999. With permission from Elsevier.

process that requires close collaboration of bioengineers, neuroscientists, and peripheral nerve surgeons. In this article we discuss the different steps that are involved in the design of an ideal nerve conduit for peripheral nerve repair, including the choice of biomaterial and fabrication technique and the various potential modifications to the common hollow nerve tube. Although most modifications are aimed at increasing the nerve gap that can be bridged, it must be noted that these can also be used to improve entubulation or nerve tube repair of smaller gaps.

\section{Choice of Biomaterial and Fabrication Technique}

The choice of biomaterial and fabrication technique is an important first step in the development of a nerve tube. In general, biodegradable materials are preferred because nonbiodegradable ones eventually may lead to compression. ${ }^{8,41}$ Biodegradable nerve tubes ideally should not be toxic or elicit an immunological response (no local tissue reaction or allergic response). Synthetic biodegradable materials in an ideal situation are therefore preferred over natural ones (although most synthetic materials also cause foreign body reactions). Different synthetic biodegradable materials have been used for nerve tube fabrication (mostly polymers of lactic and glycolic acid, and caprolactone) with various fabrication techniques. Both these factors influence the physical properties of the nerve tube that are important for entubulation repair including permeability, flexibility, swelling, and degradation.

Permeability of a conduit is an important nerve tube property because nutrients and oxygen need to diffuse into the site of regeneration before the tube becomes vascularized. In addition, permeability might be needed for the viability of supportive cells (in case these are added). Also, permeability may affect the formation of the fibrin matrix in the initial stage of regeneration. ${ }^{64}$ Nerve tubes can be made permeable with different techniques (for example, by cutting holes into the wall, ${ }^{27}$ rolling of meshes, ${ }^{13,44}$ fiber spinning, ${ }^{1}$ adding salt ${ }^{58}$ or sugar crystals ${ }^{46}$ that are leached after fabrication, and injection-molding solvent evaporation ${ }^{10}$ ). Permeability, however, also depends on hydrophilic properties of the material, which can be measured from the contact angle of a water drop on the material. ${ }^{9}$

Flexibility is an important nerve tube property, especially in the repair of larger nerve gaps, because the ends might not be in the same plane/line and the gap that needs to be bridged might cross a joint. More flexible materials, however, are also often weaker, which might lead to kinking, breaking, and/or tearing of the suture from the conduit. To find the right balance between these different mechanical properties, various polymers, polymer molecular weights, and/or copolymer ratios can first best be tested in vitro. Eventually, however, bending studies will have to be performed for the nerve tube, because dimensions (wall thickness, lumen diameter, and presence of internal frameworks, in case these are added) and porosity may also affect the mechanical properties. Ideally, the influence of degradation on the mechanical properties of the nerve tube should also be determined. 6,39

Swelling and degradation are important nerve tube properties, because swelling might occlude the lumen for regeneration or cause compression of regenerated axons. The rate of degradation might contribute to this swelling by the formation of small degradation products that increase the osmotic pressure of the conduit. ${ }^{10,14}$ Too rapid 
Designing ideal conduits for peripheral nerve repair

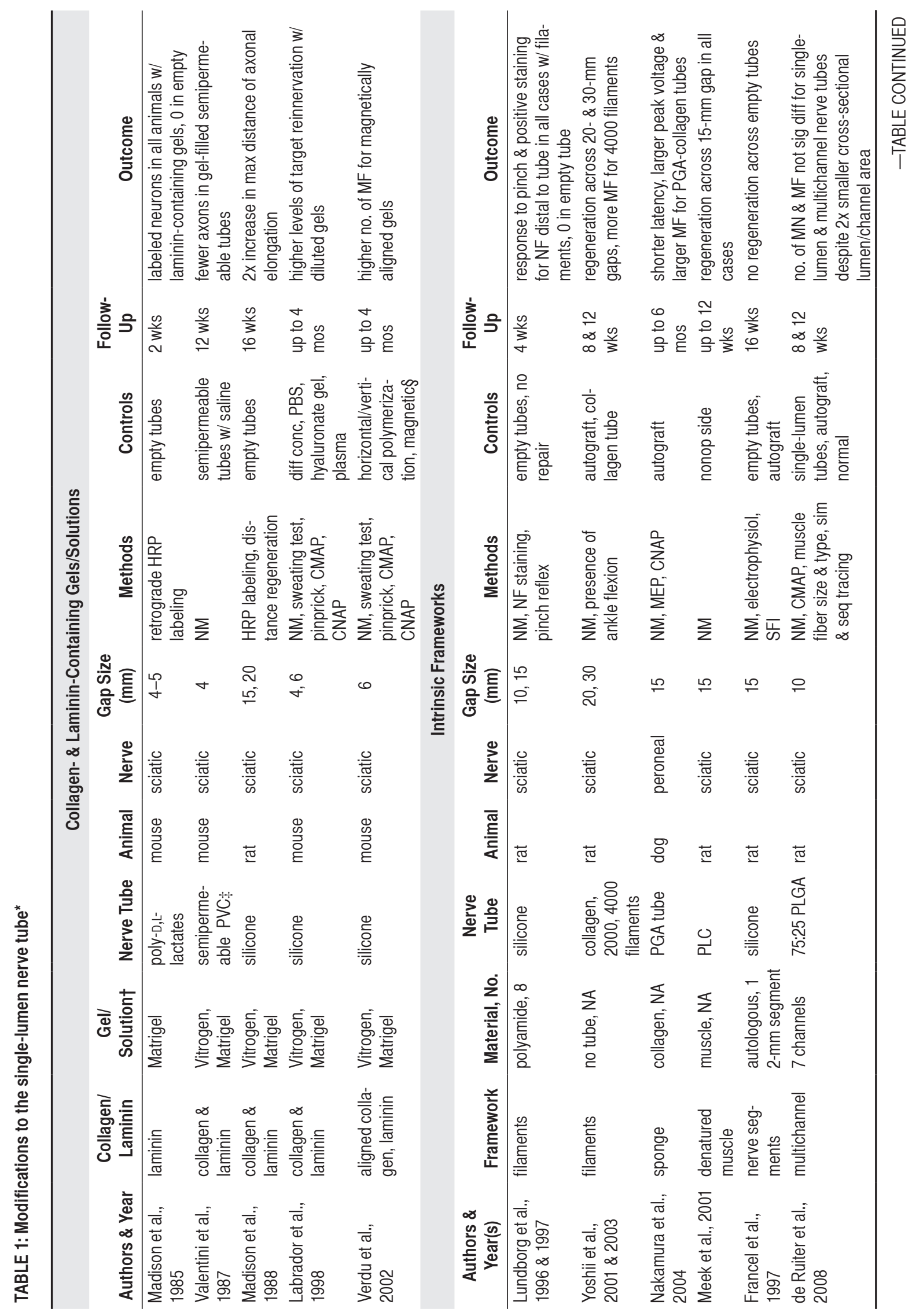


G. C. W. de Ruiter et al.

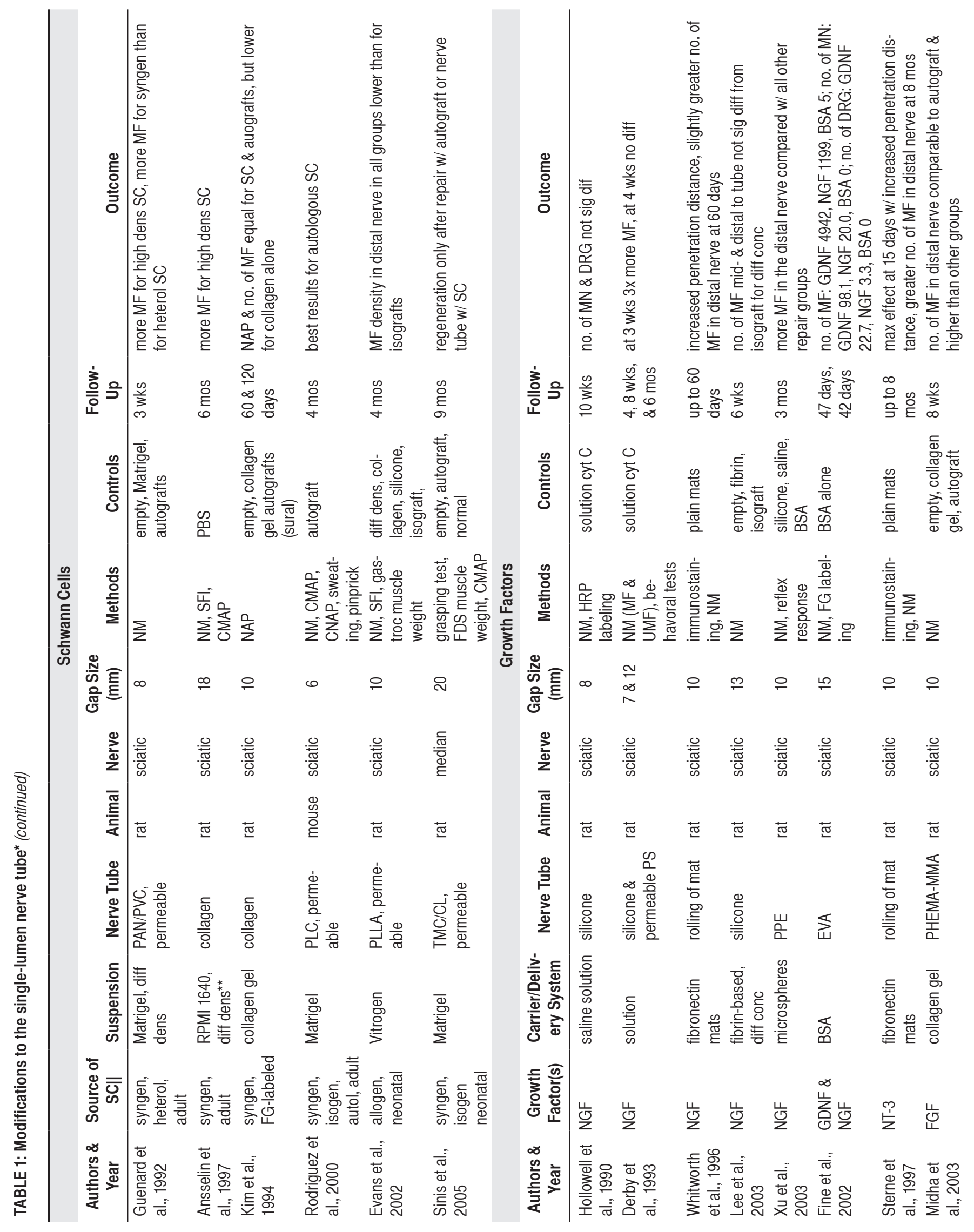




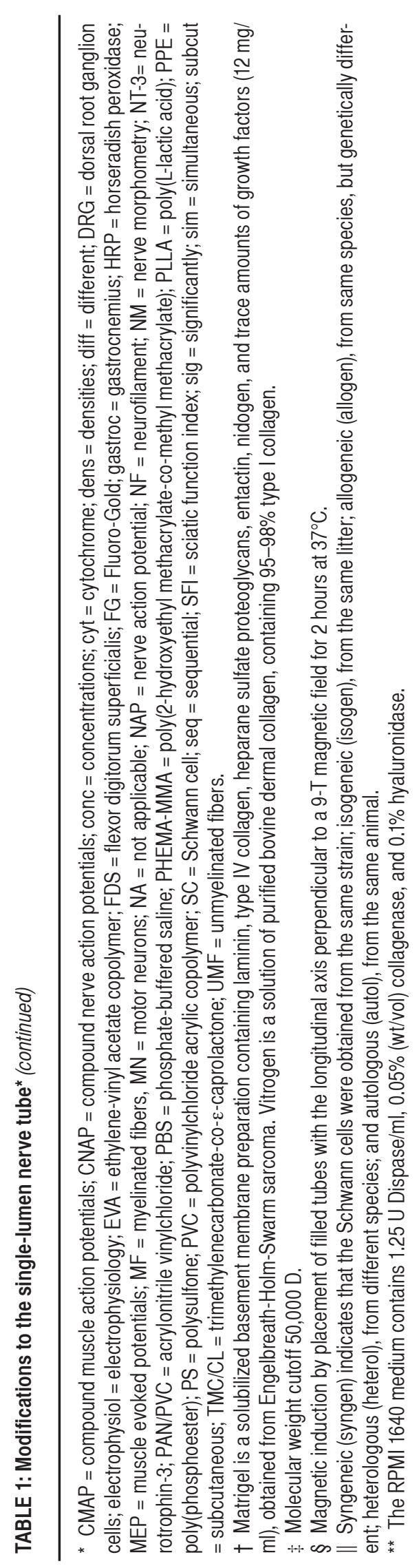

degradation may lead to swelling, but too slow degradation may later lead to compression and/or a chronic foreign body reaction. The ideal nerve tube should remain intact for the time axons need to regenerate across the nerve gap and then degrade gradually with minimal swelling and foreign body reaction. As for the mechanical properties, by changing the nerve tube dimension ${ }^{14}$ or copolymer ratio, ${ }^{10}$ the swelling and degradation properties may be optimized.

In conclusion, one should consider the desired physical properties of the nerve tube in choosing the biomaterial and fabrication technique. These properties can best first be tested in vitro. We have recently introduced a series of methods to characterize nerve tubes, especially for nerve tubes with more complex internal structures. ${ }^{10}$ Permeability of single-lumen and multichannel nerve tubes was tested from the rate of diffusion of different size fluorescent dextran molecules from the outside of the tube to the inside of the lumen/channels by comparing the color intensity on the inside to the color intensity of the known outside concentration. Mechanical properties were analyzed by 3-point bending on a dynamic mechanical analyzer. The ends of the nerve tube rested on a holder of 2 points, and a third point was lowered from above in between those 2 points with increasing force. Stiffness was subsequently calculated from the force needed to displace the tube. Swelling of tubes made of different ratios of PLGA (50:50, 75:25, and 85:15) was analyzed for the mass swelling ratio and the change in nerve tube dimensions. In the same experiment degradation was determined for the mean molecular weight of the residual tubes with gel permeation chromatography. The results of this study demonstrated that swelling of the tubes increased for lower PLGA ratios, probably as a result of more rapid degradation. Currently, however, the choice of biomaterials is still limited. Novel polymers with controlled physical properties are therefore being developed. ${ }^{26}$

In addition to these nerve tube properties, the ideal nerve tube should also be easy to handle and suture (transparent is preferable), and must be capable of being sterilized without compromising the physical properties. Finally, any modifications will also need to be considered in the choice of biomaterial and fabrication technique.

\section{Modifications to the Single-Lumen Nerve Tube}

Different types of modifications to the common hollow nerve tube have been investigated (Fig. 1 and Table 1). These modifications can grossly be divided into separate categories of collagen- and laminin-containing gels, internal frameworks, supportive cells, growth factors, and conductive polymers, but combinations have also already been used. Table 1 summarizes the details of some of the studies that have investigated these different modifications. Most modifications have been shown to increase the gap that can be bridged from 10 to $15-20 \mathrm{~mm}$ in a sciatic nerve model in rats. More recently, some modifications have also been applied in clinical nerve repair (for example, an interposed nerve segment in PGA tube repair of a $4-\mathrm{cm}$ gap in the median nerve, ${ }^{25}$ collagen sponges in 
PGA nerve tube repair of facial nerve branches, ${ }^{25 a}$ and PGA filaments in chitosan nerve tube repair of a $35-\mathrm{mm}$ gap in the median nerve ${ }^{18}$ ). In the paragraphs that follow, we only discuss the mechanisms by which these modifications might enhance regeneration, the factors that must be considered in design and analysis of the nerve tube, and the practical application of these modifications in patients.

\section{Collagen- and Laminin-Containing Gels/Solutions}

Collagen- and laminin-containing gels can enhance regeneration by the formation of a fibrin matrix for the guidance of regeneration. This matrix is also formed in the repair of defects up to $1 \mathrm{~cm}$ in empty hollow nerve tubes, ${ }^{59}$ but it does not form in the repair of larger defects. The addition of collagen and laminin gels or solutions can enhance regeneration by the presence of a larger amount of matrix components and potentially by a more homogeneous distribution. This prefilling with extra matrix components may provide a substrate for the early ingrowth of neural and nonneural cells and the binding of neurotrophic factors. Longitudinal alignment of these components (for example, by magnetic induction) may further enhance regeneration. ${ }^{55}$ Different factors must be considered in the use of collagen- and laminin-containing gels including the concentration of the gel/solution and the presence of pores/permeability of the nerve tube, which may interfere with the organization of the matrix..$^{54}$ Practically, collagen- and laminin-containing gels can be easily added to the nerve tube (the ends should be sealed to prevent leakage). However, a disadvantage often is the source of the collagen and laminin (tumor cells or bovine source [Table 1]), although recently laminin-derived oligopeptides have also been synthesized. ${ }^{63}$ These lamininderived peptides can also be used to coat the inside of nerve tubes and internal filaments ${ }^{38}$ to provide guiding cues for regenerating axons.

\section{Intrinsic Frameworks}

Intrinsic frameworks such as filaments, collagen sponges, denatured muscles, and multichannel nerve tubes may enhance regeneration by stabilization of the fibrin matrix that is formed inside the nerve tube and/or contact guidance (Table 1). In addition, the internal structure provides more surface area for cell attachment and local release of incorporated growth factors. Interposed nerve segments (the so-called stepping-stone procedure) may increase the gap that can be bridged by providing a source of Schwann cells, trophic factors, and extracellular matrix molecules in the middle of the tube or between two tubes.

In the design of conduits with modified microarchitecture it is important to realize that internal structure may affect the physical properties of the nerve tube (for example, permeability and flexibility) and reduces the total cross-sectional area that is available for regeneration. Also, in the in vivo analysis it is important to realize that the internal structure may interfere with the accuracy of regeneration across the nerve tube. In our opinion, results should therefore not only be analyzed with standard methods, such as nerve morphometry and electrophysiology, but also with, for example, simultaneous and sequential retrograde tracing. In the most commonly used model of experimental nerve repair, the rat sciatic nerve model, 2 different tracers can be applied simultaneously to the tibial and peroneal nerve branches to determine the dispersion of regenerating axons originating from the same neuron, or the 2 tracers can be applied to the same nerve branch before and after repair to determine the correct direction of regenerating axons. ${ }^{11}$

As for the practical application, the number of filaments and channels that can be introduced to the nerve tubes is currently limited by the size in which these can be produced. Furthermore, it is important to realize that longitudinally oriented structures might not mimic the fascicular structure of the nerve, which frequently consists of an intraneural plexus. In the future, this problem might be overcome by reconstructing the internal fascicular structure of the nerve with 3D printing or stereolithography. ${ }^{31,32}$

\section{Supportive Cells}

The addition of supportive cells, especially Schwann cells, to the nerve tube probably is the most extensively investigated modification to the single-lumen nerve tube. Schwann cells might enhance regeneration by different mechanisms. In the repair of small defects with empty hollow nerve tubes, Schwann cells are also involved in the process of regeneration. After weeks of implantation they migrate along the fibrin matrix that has formed inside the nerve tube from both the proximal and distal nerve ends. Again, this matrix does not form if the gap is too long. Schwann cells might increase the gap that can be bridged by forming a cable along which axons can regenerate. Other mechanisms by which Schwann cells might enhance regeneration are the production of extracellular matrix molecules (for example, laminin) and growth factors (for example, nerve growth factor).

In the design of the conduit, not only permeability is an important property to allow the diffusion of nutrients and oxygen, but also the surface texture and hydrophilic properties of the material for the attachment of cells. The latter is especially important in case microfilaments are added or the multichannel structure is used to increase the surface area for cell attachment. In the in vivo analysis, different factors must be considered including the purity of cell culture (potential contamination with fibroblasts), the source of cells (for example, neonatal or adult, and heterologous or autologous, see Table 1), the medium in which Schwann cells are suspended, and the density of Schwann cell suspension. Furthermore, in the analysis of results it is important to realize that endogenous Schwann cells might contribute to the success of regeneration and that the addition of Schwann cells might induce branching of regenerating axons. These problems can be overcome by labeling Schwann cells ${ }^{28}$ and using retrograde tracing techniques to determine the number of regenerated motor and sensory neurons. As for the clinical use of Schwann cells it is important to realize that these cells will have to be harvested (and still require the use of an autograft, because autologous cells are preferred) and 


\section{Designing ideal conduits for peripheral nerve repair}

will have to be cultured before reconstructive surgery. Although the difficulty of harvesting might be overcome by the differentiation of bone marrow stem cells from the patient into Schwann cells, ${ }^{43}$ the culturing of these cells will be demanding (require special facilities) and cannot be readily performed in an acute setting at this time. Advantages of culturing, however, are that the Schwann cell phenotype can be modulated, for example into motor or sensory Schwann cells, ${ }^{23}$ and that the cells can be genetically modified to overexpress certain factors.

\section{Growth Factors}

Different growth factors including NGF, GDNF, neurotrophin-3, and FGF have been added to single-lumen nerve tubes (Table 1). Growth factors may enhance regeneration by several mechanisms, for example, by promoting axonal outgrowth and neuronal survival. These effects may be particularly interesting for the delayed repair of nerve lesions (which is often the case in the repair of larger nerve gaps). Another interesting application of growth factors might be that they can be used to selectively stimulate different subgroups of motor and sensory neurons.

As for the design of the nerve tube, growth factors can be added directly (in solution) or through a delivery system. Delivery systems are generally preferred, because the effect of growth factors is often dose dependent and requires the release over extended periods of time. Besides, solutions may leak from the nerve tube. Different carriers and delivery systems have been used including absorption to fibronectin mats, collagen matrices, BSA, and microspheres (Table 1). An advantage of matrices is that they also provide an internal structure for regeneration. An advantage of microspheres is that they can be added to the structure of the nerve tube (wall or internal structure) during the fabrication process. Different gradients of growth factors can thereby be incorporated over the length of the nerve tube to attract regenerating axons and to sustain regeneration throughout the tube to prevent trapping of axons (the so-called candy store phenomenon). ${ }^{53}$ Currently, however, there is still little information on the release kinetics of incorporated growth factors and their biological activity. Ideally, these characteristics should be tested in vitro and in vivo. Furthermore, in the in vivo analysis, it is important to include both positive and negative controls, and to correct again (as discussed for the addition of Schwann cells) for the potential effect on branching of regenerating axons by using retrograde tracing.

For clinical use, nerve tubes with incorporated growth factors are, in our opinion, more practical than the addition of Schwann cells because of the special facilities required for the culturing of the cells (see Supportive Cells). Limitations of growth factors, however, might be the loss of biological activity over time or after sterilization of the nerve tubes.

\section{Conductive Polymers}

Finally, conductive polymers (for example, polypyrrole) might enhance regeneration by accelerated axonal elongation on the charged surface. ${ }^{2,50}$ In addition, electrical stimulation might be used to guide axonal regeneration. Currently conductive polymers are not frequently used, probably because most are nonbiodegradable, but with the development of novel polymers, these materials may provide interesting opportunities for nerve repair.

\section{Conclusions}

We have discussed the various steps that are involved in the design of an ideal conduit for peripheral nerve repair. In the first step (the choice of biomaterial and fabrication technique), it is important to consider the desired physical properties of the tube. Especially in the repair of larger nerve gaps, permeable and flexible tubes are preferred with controlled degradation rates and limited swelling. Second, the design of the common hollow nerve tube can be modified to enhance regeneration: various factors can be added including laminin, collagen, Schwann cells, growth factors, and internal filaments, and the nerve tube microarchitecture can be modified. We believe that a combination of various modifications (for example microfilaments with Schwann cells or multichannel nerve tubes with incorporated growth factors) with controlled physical properties of the conduit will ultimately lead to the best results of regeneration. More research is still needed to solve some of the limitations discussed in this article. In our opinion, the future of nerve tube repair is bright provided that newly developed conduits are analyzed in detail in vitro and in vivo before clinical use.

\section{Disclosure}

Dr. Spinner is a consultant for Mayo Medical Ventures. None of the other authors report a conflict of interest concerning the materials or methods used in this study or the findings specified in this paper.

\section{References}

1. Aebischer P, Guenard V, Valentini RF: The morphology of regenerating peripheral nerves is modulated by the surface microgeometry of polymeric guidance channels. Brain Res 531:211-218, 1990

2. Aebischer P, Valentini RF, Dario P, Domenici C, Galletti PM: Piezoelectric guidance channels enhance regeneration in the mouse sciatic nerve after axotomy. Brain Res 436:165-168, 1987

3. Ansselin AD, Fink T, Davey DF: Peripheral nerve regeneration through nerve guides seeded with adult Schwann cells. Neuropathol Appl Neurobiol 23:387-398, 1997

4. Archibald SJ, Krarup C, Shefner J, Li ST, Madison RD: A collagen-based nerve guide conduit for peripheral nerve repair: an electrophysiological study of nerve regeneration in rodents and nonhuman primates. J Comp Neurol 306:685-696, 1991

5. Archibald SJ, Shefner J, Krarup C, Madison RD: Monkey median nerve repaired by nerve graft or collagen nerve guide tube. J Neurosci 15:4109-4123, 1995

6. Belkas JS, Munro CA, Shoichet MS, Johnston M, Midha R: Long-term in vivo biomechanical properties and biocompatibility of poly(2-hydroxyethyl methacrylate-co-methyl methacrylate) nerve conduits. Biomaterials 26:1741-1749, 2005

7. Bertleff MJ, Meek MF, Nicolai JP: A prospective clinical evaluation of biodegradable neurolac nerve guides for sensory 
nerve repair in the hand. J Hand Surg [Am] 30:513-518, 2005

8. Braga-Silva J: The use of silicone tubing in the late repair of the median and ulnar nerves in the forearm. J Hand Surg [Br] 24:703-706, 1999

9. Busscher H, van Pelt AWJ, de Jong HP, Arends J: Effect of spreading pressure on surface free energy determinations by means of contact angle measurements. J Colloid Interface Sci 95:23-27, 1983

10. de Ruiter GC, Onyeneho IA, Liang ET, Moore MJ, Knight AM, Malessy MJ, et al: Methods for in vitro characterization of multichannel nerve tubes. J Biomed Mater Res A 84:643651,2008

11. de Ruiter GC, Spinner RJ, Malessy MJ, Moore MJ, Sorenson EJ, Currier BL, et al: Accuracy of motor axon regeneration across autograft, single-lumen, and multichannel poly(lacticco-glycolic acid) nerve tubes. Neurosurgery 63:144-145, 2008

12. de Ruiter GC, Spinner RJ, Yaszemski MJ, Windebank AJ, Malessy MJ: Nerve tubes for peripheral nerve repair. Neurosurg Clin N Am 20: 91-105, 2009

13. Dellon AL, Mackinnon SE: An alternative to the classical nerve graft for the management of the short nerve gap. Plast Reconstr Surg 82:849-856, 1988

14. den Dunnen W, van der Lei B, Robinson PH, Holwerda A, Pennings AJ, Schakenraad JM: Biological performance of a degradable poly(lactic acid- $\varepsilon$-caprolactone) nerve guide: influence of tube dimensions. J Biomed Mater Res 29:757766,1995

15. den Dunnen WF, van der Lei B, Schakenraad JM, Stokroos I, Blaauw E, Bartels H, et al: Poly(DL-lactide-epsilon-caprolactone) nerve guides perform better than autologous nerve grafts. Microsurgery 17:348-357, 1996

16. Derby A, Engleman VW, Frierdich GE, Neises G, Rapp SR, Roufa DG: Nerve growth factor facilitates regeneration across nerve gaps: morphological and behavioral studies in rat sciatic nerve. Exp Neurol 119:176-191, 1993

17. Evans GR, Brandt K, Katz S, Chauvin P, Otto L, Bogle M, et al: Bioactive poly(L-lactic acid) conduits seeded with Schwann cells for peripheral nerve regeneration. Biomaterials 23:841-848, 2002

18. Fan W, Gu J, Hu W, Deng A, Ma Y, Liu J, et al: Repairing a 35-mm-long median nerve defect with a chitosan/PGA artificial nerve graft in the human: a case study. Microsurgery 28:238-242, 2008

19. Fine EG, Decosterd I, Papaloizos M, Zurn AD, Aebischer P: GDNF and NGF released by synthetic guidance channels support sciatic nerve regeneration across a long gap. Eur J Neurosci 15:589-601, 2002

20. Francel PC, Francel TJ, Mackinnon SE, Hertl C: Enhancing nerve regeneration across a silicone tube conduit by using interposed short-segment nerve grafts. J Neurosurg 87:887892,1997

21. Guénard V, Kleitman N, Morrissey TK, Bunge RP, Aebischer P: Syngeneic Schwann cells derived from adult nerves seeded in semipermeable guidance channels enhance peripheral nerve regeneration. J Neurosci 12:3310-3320, 1992

22. Harley BA, Spilker MH, Wu JW, Asano K, Hsu H-P, Spector M, Yannas IV: Optimal degradation rate for collagen chambers used for regeneration of peripheral nerves over long gaps. Cells Tissues Organs 176: 153-165, 2004

23. Hoke A, Redett R, Hameed H, Jari R, Zhou C, Li ZB, et al: Schwann cells express motor and sensory phenotypes that regulate axon regeneration. J Neurosci 26:9646-9655, 2006

24. Hollowell JP, Villadiego A, Rich KM: Sciatic nerve regeneration across gaps within silicone chambers: long-term effects of NGF and consideration of axonal branching. Exp Neurol 110:45-51, 1990

25. Hung V, Dellon AL: Reconstruction of a 4-cm human me- dian nerve gap by including an autogenous nerve slice in a bioabsorbable nerve conduit: case report. J Hand Surg [Am] 33:313-315, 2008

25a. Inada Y, Hosoi H, Yamashita A, Morimoto S, Tatsumi H, Notazawa S, et al: Regeneration of peripheral motor nerve gaps with a polyglycolic acid-collagen tube: technical case report. Neurosurgery 61:E1105-1107, 2007

26. Jabbari E, Wang S, Lu L, Gruetzmacher JA, Ameenuddin S, Hefferan TE, et al: Synthesis, material properties, and biocompatibility of a novel self-cross-linkable poly(caprolactone fumarate) as an injectable tissue engineering scaffold. Biomacromolecules 6:2503-2511, 2005

27. Jenq CB, Coggeshall RE: Nerve regeneration through holey silicone tubes. Brain Res 361:233-241, 1985

28. Kim DH, Connolly SE, Kline DG, Voorhies RM, Smith A, Powell M, et al: Labeled Schwann cell transplants versus sural nerve grafts in nerve repair. J Neurosurg 80:254-260, 1994

29. Labrador RO, Buti M, Navarro X: Influence of collagen and laminin gels concentration on nerve regeneration after resection and tube repair. Exp Neurol 149:243-252, 1998

30. Lee AC, Yu VM, Lowe JB III, Brenner MJ, Hunter DA, Mackinnon SE, et al: Controlled release of nerve growth factor enhances sciatic nerve regeneration. Exp Neurol 184:295-303, 2003

31. Lee KW, Wang S, Fox BC, Ritman EL, Yaszemski MJ, Lu L: Poly(propylene fumarate) bone tissue engineering scaffold fabrication using stereolithography: effects of resin formulations and laser parameters. Biomacromolecules 8: 1077-1084, 2007

32. Lee KW, Wang S, Lu L, Jabbari E, Currier BL, Yaszemski MJ: Fabrication and characterization of poly(propylene fumarate) scaffolds with controlled pore structures using 3-dimensional printing and injection molding. Tissue Eng 12:2801-2811, 2006

33. Li ST, Archibald SJ, Krarup C, Madison RD: Peripheral nerve repair with collagen conduits. Clin Mater 9:195-200, 1992

34. Lundborg G, Dahlin L, Dohi D, Kanje M, Terada N: A new type of "bioartificial" nerve graft for bridging extended defects in nerves. J Hand Surg [Br] 22:299-303, 1997

35. Lundborg G, Kanje M: Bioartificial nerve grafts. A prototype. Scand J Plast Reconstr Surg Hand Surg 30:105-110, 1996

36. Madison R, da Silva CF, Dikkes P, Chiu TH, Sidman RL: Increased rate of peripheral nerve regeneration using bioresorbable nerve guides and a laminin-containing gel. Exp Neurol 85:767-772, 1985

37. Madison RD, Da Silva CF, Dikkes P: Entubulation repair with protein additives increases the maximum nerve gap distance successfully bridged with tubular prostheses. Brain Res 447:325-334, 1988

38. Matsumoto K, Ohnishi K, Kiyotani T, Sekine T, Ueda H, Nakamura T, et al: Peripheral nerve regeneration across an 80$\mathrm{mm}$ gap bridged by a polyglycolic acid (PGA)-collagen tube filled with laminin-coated collagen fibers: a histological and electrophysiological evaluation of regenerated nerves. Brain Res 868:315-328, 2000

39. Meek MF, Jansen K, Steendam R, van Oeveren W, van Wachem PB, van Luyn MJ: In vitro degradation and biocompatibility of poly(DL-lactide-epsilon-caprolactone) nerve guides. J Biomed Mater Res A 68:43-51, 2004

40. Meek MF, Robinson PH, Stokroos I, Blaauw EH, Kors G, den Dunnen WF: Electronmicroscopical evaluation of shortterm nerve regeneration through a thin-walled biodegradable poly(DLLA-epsilon-CL) nerve guide filled with modified denatured muscle tissue. Biomaterials 22:1177-1185, 2001

41. Merle M, Dellon AL, Campbell JN, Chang PS: Complications from silicon-polymer intubulation of nerves. Microsurgery 10:130-133, 1989

42. Midha R, Munro CA, Dalton PD, Tator CH, Shoichet MS: Growth factor enhancement of peripheral nerve regenera- 


\section{Designing ideal conduits for peripheral nerve repair}

tion through a novel synthetic hydrogel tube. J Neurosurg 99:555-565, 2003

43. Mimura T, Dezawa M, Kanno H, Sawada H, Yamamoto I: Peripheral nerve regeneration by transplantation of bone marrow stromal cell-derived Schwann cells in adult rats. J Neurosurg 101:806-812, 2004

44. Molander H, Olsson Y, Engkvist O, Bowald S, Eriksson I: Regeneration of peripheral nerve through a polyglactin tube. Muscle Nerve 5:54-57, 1982

45. Nakamura T, Inada Y, Fukuda S, Yoshitani M, Nakada A, Itoi $S$, et al: Experimental study on the regeneration of peripheral nerve gaps through a polyglycolic acid-collagen (PGA-collagen) tube. Brain Res 1027:18-29, 2004

46. Rodriguez FJ, Gomez N, Perego G, Navarro X: Highly permeable polylactide-caprolactone nerve guides enhance peripheral nerve regeneration through long gaps. Biomaterials 20:1489-1500, 1999

47. Rodriguez FJ, Verdu E, Ceballos D, Navarro X: Nerve guides seeded with autologous schwann cells improve nerve regeneration. Exp Neurol 161:571-584, 2000

48. Rosson GD, Williams EH, Dellon AL: Motor nerve regeneration across a conduit. Microsurgery [epub ahead of print], 2008

49. Schlosshauer B, Dreesmann L, Schaller HE, Sinis N: Synthetic nerve guide implants in humans: a comprehensive survey. Neurosurgery 59:740-748, 2006

50. Schmidt CE, Shastri VR, Vacanti JP, Langer R: Stimulation of neurite outgrowth using an electrically conducting polymer. Proc Natl Acad Sci U S A 94:8948-8953, 1997

51. Sinis N, Schaller HE, Schulte-Eversum C, Schlosshauer B, Doser M, Dietz K, et al: Nerve regeneration across a 2-cm gap in the rat median nerve using a resorbable nerve conduit filled with Schwann cells. J Neurosurg 103:1067-1076, 2005

52. Sterne GD, Brown RA, Green CJ, Terenghi G: Neurotrophin-3 delivered locally via fibronectin mats enhances peripheral nerve regeneration. Eur J Neurosci 9:1388-1396, 1997

53. Tannemaat MR, Eggers R, Hendriks WT, de Ruiter GC, van Heerikhuize JJ, Pool CW, et al: Differential effects of lentiviral vector-mediated overexpression of nerve growth factor and glial cell line-derived neurotrophic factor on regenerating sensory and motor axons in the transected peripheral nerve. Eur J Neurosci 28:1467-1479, 2008

54. Valentini RF, Aebischer P, Winn SR, Galletti PM: Collagenand laminin-containing gels impede peripheral nerve regeneration through semipermeable nerve guidance channels. Exp Neurol 98:350-356, 1987
55. Verdu E, Labrador RO, Rodriguez FJ, Ceballos D, Fores J, Navarro X: Alignment of collagen and laminin-containing gels improve nerve regeneration within silicone tubes. Restor Neurol Neurosci 20:169-179, 2002

56. Weber RA, Breidenbach WC, Brown RE, Jabaley ME, Mass DP: A randomized prospective study of polyglycolic acid conduits for digital nerve reconstruction in humans. Plast Reconstr Surg 106:1036-1038, 2000

57. Whitworth IH, Brown RA, Dore CJ, Anand P, Green CJ, Terenghi G: Nerve growth factor enhances nerve regeneration through fibronectin grafts. J Hand Surg [Br] 21:514-522, 1996

58. Widmer MS, Gupta PK, Lu L, Meszlenyi RK, Evans GR, Brandt K, et al: Manufacture of porous biodegradable polymer conduits by an extrusion process for guided tissue regeneration. Biomaterials 19:1945-1955, 1998

59. Williams LR, Longo FM, Powell HC, Lundborg G, Varon S: Spatial-temporal progress of peripheral nerve regeneration within a silicone chamber: parameters for a bioassay. J Comp Neurol 218:460-470, 1983

60. Xu X, Yee WC, Hwang PY, Yu H, Wan AC, Gao S, et al: Peripheral nerve regeneration with sustained release of poly(phosphoester) microencapsulated nerve growth factor within nerve guide conduits. Biomaterials 24:2405-2412, 2003

61. Yoshii S, Oka M: Peripheral nerve regeneration along collagen filaments. Brain Res 888:158-162, 2001

62. Yoshii S, Oka M, Shima M, Taniguchi A, Akagi M: Bridging a 30-mm nerve defect using collagen filaments. J Biomed Mater Res 67A:467-474, 2003

63. Yu TT, Shoichet MS: Guided cell adhesion and outgrowth in peptide-modified channels for neural tissue engineering. Biomaterials 26:1507-1514, 2005

64. Zhao Q, Dahlin LB, Kanje M, Lundborg G: Repair of the transected rat sciatic nerve: matrix formation within implanted silicone tubes. Restor Neurol Neurosci 5:197-204, 1993

Manuscript submitted October 17, 2008.

Accepted November 13, 2008.

Address correspondence to: Robert J. Spinner, M.D., Department of Neurosurgery, Mayo Clinic Rochester, 200 First Street SW, Rochester, Minnesota 55905. email: spinner.robert@mayo.edu. 